\title{
Polyurethane resins filled with inorganic waste particles
}

Petr Valášek, Miroslav Müller

Department of Material Science and Manufacturing Technology, Faculty of Engineering, Czech University of Life Sciences in Prague. E-mail: valasekp@tf.czu.cz.

Polyurethane resins belong to a group of polymers which can be easily filled with inorganic particles. Filling of the polymeric materials, either with particles or fibres, influences resulted properties of the arisen material - composite. The particle fillers can improve a wear resistance, they can optimize tensile characteristics and reduce the polymer price. The paper describes the polyurethane resin as a material recyclation bearer of the waste inorganic particles of the corundum, the artificial garnet and the silicon carbide. The experiment results certified that the mutual interaction of stated phases creates the wear resistant material which can be used owing to the polyurethane elasticity in the sphere of a cementing or at creating the material surface layers.

Keywords: abrasive wear, deformation, hardness, recyclation

\section{Acknowledgement}

This paper was created when solving the grant IGA TF ČZU No. 31140/1312/3104.

\section{References}

[1] MLEZIVA, J., SNUPAREK J.(2000). Polymery výroba, struktura, vlastnosti a použití, 544 p. Sobotáles, Prague.

[2] EHRENSTEIN, G. W. (2009). Polymerní kompozitní materiály $1^{\text {th }}$ ed., 351 p. Nakladatelství Scientia, Prague.

[3] LISKUTIN, P., MAZAL, P., et al. (2011). Modifikace kompozitu Al-Al2O3 malym množstvim Al2O3. Strojírenská technologie, No. 4, pp. $41-47$.

[4] XIA JIA, XIAOMEI LING. (2005). Influence of $\mathrm{Al}_{2} \mathrm{O}_{3}$ reinforcement on the abrasive wear characteristic of $\mathrm{Al}_{2} \mathrm{O}_{3} / \mathrm{PA}_{1010}$ composite coatings. Wear. Vol. 258, No. 9, pp.1342 - 1347.

[5] SATAPATHY B.K., BIJWE, J. (2002). Analysis of simultaneous influence of operating variables on abrasive wear of phenolic composites. Wear, Vol. 253, pp. $787-794$.

[6] MULLER, M., VALASEK, P. (2012). Abrasive wear effect on Polyethylene, Polyamide 6 and polymeric particle composites. Manufacturing Technology, Vol. 12, pp. 55 - 59 .

[7] KEJVAL, J., MÜLLER, M., HENC, P. (2012). Mechanické vlastnosti a „two-body“ abrazívní opotřebení polymerních částicových kompozitů. Strojírenská technologie, Vol. 17, No. 1-2, pp. 33 - 38.

[8] OLEA-MEJIA O., BROSTOW W., BUCHMAN E. (2010). Wear Resistance and Wear Mechanisms in Polymer plus Metal Composites. Journal of nanoscience and nanotechnology. Vol. 10, pp. $8254-8259$.

[9] KU, H., WONG, P. (2012). Contrast on Tensile and Flexural Properties of Glass Powder Reinforced Epoxy Composites: Pilot Study. Journal of applied polymer science, Vol. 123, pp.152 - 161.

[10] VALASEK, P., MULLER, M. (2012). Influence of bonded abrasive particles size on wear of polymeric particle composites based on waste. Manufacturing Technology, Vol. 12, No. 13, pp. 268 - 272.

[11] MULLER, M., VALASEK, P. (2010). Polymerní kompozity na bázi zpevňujících částic odpadů z procesu mechanické povrchové úpravy. Strojírenská technologie, Vol. 14, No. 0, pp. 183 - 186.

[12] NOVAK, M. (2011). Surface duality hardened steels after grinding. Manufacturing technology, Vol. 11, pp. 55 - 59.

[13] VAlASEK, P., MULlER, M., CHOCHOLOUS, P. (2012). Polymerní částicové kompozity na bázi odpadu s obsahem oxidu křemičitého. Strojírenská technologie, Vol. 17, No. 1-2, pp. 122 - 127.

[14] VALASEK, P., MULLER, M. (2012). Polymeric particle composites with filler saturated matrix. Manufacturing Technology, Vol. 12, No. 13 , pp. $272-276$.

[15] BERTHELOT, J. M. (1999). Composite Materials - Mechanical Behavior and Structural Analysis. Mechanical engineering series. 635 p., Springer, New York.

[16] VALASEK, P., MÜLLER, M., KEJVAL, J. (2012). Faktory limitující použití polymerních částicových kompozitů - pórovitost. Strojírenská technologie, Vol. 17, Nr. 3, pp. $192-197$.

[17] MULLER, M., PAVELKA, R. (2010). Jakost nátěrových systémů používaných v automobilovém průmyslu. Strojírenská technologie, Vol. 14, No. 0, pp. $187-190$. 